\title{
Seismic vulnerability analysis for masonry hospital structures: Expeditious and detailed methods
}

\author{
A. Ciavattone \& A. Vignoli \\ Department of Civil and Environmental Engineering, University of Florence, Florence, Italy \\ H.G. Matthies \\ Institute of Scientific Computing, University of Braunschweig, Braunschweig, Germany
}

\begin{abstract}
The assessment of the structural vulnerability for existing buildings in Italy is a key aspect for the seismic risk reduction, in particular for strategic and relevant buildings, because of their importance for the civil protection. Different approaches can be used: expeditious/empirical methods, based on qualitative evaluations, analytical methods, based on detailed models, or hybrid methods, based instead on simplified numerical models. In case of a wide sample of buildings, the use of empirical methods is necessary in order to obtain a first screening of the buildings and to delineate a vulnerability classification, which can be used as a priority list for further detailed analyses. In this work, the comparison among an empirical approach (Vulnerability Index Method, G.N.D.T., 1993) and a detailed approach (pushover analysis) on a sample of 20 masonry hospital structures is carried out. The critical analysis of the results has allowed the development of a new empirical assessment procedure, able to estimate the peak ground acceleration of capacity of masonry structures, using the information required by the II Level Vulnerability Form (G.N.D.T., 1993).
\end{abstract}

\section{INTRODUCTION}

The Italian territory is characterized by a considerable seismic activity, due to its geographical position; moreover, many existing structures are not properly designed against seismic actions, since this approach has been introduced throughout the country only in recent years. Considering these two aspects, it is possible to affirm that Italy is a nation with a relevant seismic risk. Particular attention must be paid to the buildings that, due to their functions, have a relevant or strategic role in the civil protection, such as schools, hospitals etc...

In order to reduce the seismic risk for the Italian built asset, it is important to focus on the vulnerability assessment, trying to highlight the objects which could show the most critical conditions in case of a seismic event.

\section{SEISMIC VULNERABILITY EVALUATION}

\subsection{General remarks}

Many approaches are available in literature for the seismic vulnerability evaluation, considering different levels of detail:
- expeditious empirical methods, mainly based on qualitative evaluations, necessary in case of the seismic vulnerability analysis of a wide sample of buildings, for which a detailed analysis for all the structures can be too much expensive. This approach is often used for analysis on a territorial scale;

- analytical/mechanical methods, based on detailed evaluations: they allow the seismic vulnerability study through analyses of the structural behaviour of the considered building, using numerical models (linear or not linear) with different types of analysis (static or dynamic);

- hybrid methods, which are a combination of the two methods described above, since they are based on simplified mechanical models which try to describe the behaviour of the considered structures under a seismic event, even if they do not represent a complete structural analysis. They are often used for the territorial approach, but they also give an estimation of the safety index for the considered structures.

\subsection{Expeditious methods}

The expeditious empirical methods start to be developed during the " $70 \mathrm{~s}$, with the first approaches 
based on the observation of the structural damages of past seismic events, such as the Damage Probability Matrix Method, developed by Whitman et al in 1973, which provides the use of probabilistic matrices for the prediction of the damage caused by different seismic events. These matrixes have been calibrated according to the damage suffered by over 1600 buildings after the 1971 San Fernando earthquake (California, 6.6 magnitude-Richter Scale). In this method, the basic concept is that a given structural typology has the same probability of damage for a given earthquake intensity.

A similar approach is adopted in the European Macro-seismic Scale, developed by Grünthal et al. in 1998, which proposes tables that identify different vulnerability classes considering different structural typologies, starting from rubble stone masonry and arriving to timber structures.

In the ' $80 \mathrm{~s}$, the Vulnerability Index Method has been developed by Benedetti and Petrini (1984) and the National Group for the Defence by the Earthquakes, G.N.D.T., (1993) for masonry structures at first, arriving then to the extension of the method to reinforced concrete structures. This method consists of a filling in procedure of a survey form, composed of 11 parameters (Table 1): for each parameter, the surveyor has to assign a judgment (four possibilities, from "A" - optimal condition to "D"-unfavourable condition), taking into account the brief descriptions given in the user manual, which allow a more objective decision. For each judgment of each parameter, a score is given by the method. Using the weight coefficients related to each parameter (provided in order to take into account the relative importance of each parameter

Table 1. Weights $W_{i}$ of the 11 parameters of the Vulnerability Form for masonry structures.

\begin{tabular}{lll}
\hline $\mathrm{N}^{\circ}$ & Parameter & $\mathrm{W}_{\mathrm{i}}$ \\
\hline 1 & $\begin{array}{l}\text { Type and organization of the resistant } \\
\text { system }\end{array}$ & 1.00 \\
2 & $\begin{array}{l}\text { Quality of the resistant system } \\
3\end{array}$ & 0.25 \\
4 & Conventional resistance & 1.50 \\
5 & Position of the building and foundation & 0.75 \\
6 & Planimetric configuration & var. $^{*}$ \\
7 & Elevation configuration & 0.50 \\
8 & Maximum distance among the walls & 0.25 \\
9 & Roof & var. $^{* * *}$ \\
10 & Non structural elements & 0.25 \\
11 & State of conservation & 1.00 \\
\hline
\end{tabular}

* variable in relation to the percentage of stiff and well connected floors. $* *$ variable in relation to the typology of irregularity. $* * *$ variable in relation to typology and weight of the roof. In any case, for all three parameters, $0.50 \leq \mathrm{w}_{\mathrm{i}} \leq 1.00$. in the global definition of vulnerability), it is possible to calculate a Vulnerability Index (in the following, $I_{v}$ ) as the weighted sum of the scores of each parameter, usually normalized in a $0 \%-100 \%$ range, where a low index means that the structure is not vulnerable and therefore it has a high capacity under seismic action.

Looking Table 1 , it is possible to observe the presence of some parameters directly related to the structural characteristics of the buildings, while other ones concern non structural aspects (for example, parameters 10 and 11).

Moreover, the structural aspects are related both to the global and local behaviour of the masonry structures (for example, parameter 8 is related to the distance among orthogonal walls, which considers, in an indirect way, the possibility of activation of out of plane mechanisms, while the other ones are more related to the global behaviour). For the complete definition of each parameter, see G.N.D.T., 1993.

Many other procedures have been developed in the last decades, some of them starting directly from the Vulnerability Index Method: Formisano et al. (2009) and Vicente et al. (2011) for example analyze the masonry structures in aggregate with a modified Index of Vulnerability method.

\subsection{Hybrid methods}

These methods have been developed considering simplified mechanical models, in order to get an estimation of the capacity (in terms of peak ground acceleration, $\mathrm{PGA}_{c}$ ) and of the related index of safety.

One of the most popular methods in the Italian Scientific community is the S.A.V.E. Project (Strumenti Aggiornati per la Vulnerabilità sismica del patrimonio Edilizio e dei sistemi urbani) proposed by the I.N.G.V. / G.N.D.T. Research Group in 2005: the procedure is a quite simple instrument for a first vulnerability screening of the public buildings.

The S.A.V.E. method, operating with different numerical approaches for reinforced concrete and masonry structures, considers the collapse of all the resistant systems (piers for masonry buildings, columns for r.c. structures) and calculates the related shear capacity at each level; then, by means of a static linear analysis with $1 \mathrm{~g}$ of horizontal acceleration $\left(9.81 \mathrm{~m} / \mathrm{s}^{2}\right)$, it is possible to calculate the spectral acceleration of collapse and the related peak ground acceleration of capacity, allowing the estimation of the safety index as the ratio among capacity and demand.

Several other methods have been developed starting from these ones, improving the level of 
detail or proposing different versions of the data treatment. The RE.SIS.TO Project (acronym of "REsistenza SISmica TOtale" - total seismic resistance), proposed by the University of Bologna (Chinni et al, 2013), combines the S.A.V.E. Project with the Vulnerability Index Method, leading to the calculation of the peak ground acceleration of capacity, PGA $_{c}$.

\subsection{Analytical/mechanical methods}

Analytical methods are the common procedures of structural analysis in the civil engineering field, which can be performed both with linear and non linear approaches, in dynamic or static way.

Referring to masonry structures, it is important to remind that a structure must be analyzed considering the local approach at first, which is related to the possible activation of out of plane mechanisms of single façades or portions of the structure (rocking, vertical or horizontal bending, etc...) and then the global approach, assuming that each wall reacts in its plane against the horizontal forces; the first approach (local behaviour) is related to the buildings which show a lack of connection among structural elements (orthogonal walls and floors) while the second one (global behaviour) is referred to buildings which show a box behaviour due to the effective connection among structural elements.

All these methods allow the calculation of the capacity (often expressed in terms of peak ground acceleration, $\mathrm{PGA}_{\mathrm{c}}$ ) and of the safety index, ratio among capacity and demand.

\subsection{Methods utilized in this work}

In this work, the comparison among an expeditious and a detailed method is proposed: in particular, the Vulnerability Index Method will be utilized and compared with static non linear analyses.

The comparison is carried out in order to investigate at first the level of coherence among the two approaches; then, a proposal for a new empirical method is presented, using the results obtained from both methods on a sample of masonry buildings.

\section{SAMPLE OF ANALYSIS}

\subsection{Introduction}

The sample of analysis of this work is composed of masonry hospital structures located in the Tuscany Region and, in particular, in the cities of Florence, Prato and Pistoia: the DICEA-UNIFI Research Group, during the period 2010-2011, has investigated this group of structures using a standardized procedure of survey, calculating the $I_{v}$ for each structure with the Vulnerability Index Method.

\subsection{Description of the investigated sample}

The sample of analysis is composed by 4 Healthcare Companies: AUSL 3 (Pistoia), AUSL 4 (Prato), AUSL 10 and AOUC (Florence). Each Company is composed of different Complexes (32 in total in this case), which have been subdivided into independent structural units, considering the definition contained in the Italian Code D.M. 2008: "structural unit (in the following, S.U.) is a building which has structural continuity from the ground until the top for the gravity loads and it is normally delimited by open spaces, structural joints or buildings realized with different construction methods" (D.M. 2008).

Using the available information about the historical evolution of the Complexes and investigating the structural typologies, it has been possible to subdivide the Complexes in a total of 118 masonry S.U. and 101 reinforced concrete S.U..

All the investigated structures correspond to a total volume of $1.240 .000 \mathrm{~m}^{3}$, quite equally subdivided among the two construction's techniques.

\section{VULNERABILITY SURVEY PROGRAM}

\subsection{Methodology of survey}

A standardized procedure of survey has been developed by the DICEA-UNIFI Research Group, in order to obtain a homogeneous description of all the S.U. of the sample; the survey was divided into different parts that have led to the realization of descriptive reports, organized in the following way:

- description of the Hospital Complex from the historical - functional point of view;

- identification of the S.U., through the observation of the technical joints or structural discontinuities;

- brief description of each S.U. (number of stories, volume, shape of the building, period of realization, construction typologies, state of conservation etc...);

- photographic documentation with the localization of the points of view for each photo, highlighting the relevant aspects for the definition of the vulnerability (stairs, elevators, situations of visible deterioration etc...);

- structural plans of each level of the considered S.U., with information regarding the typology and main direction of the floors;

- $2^{\circ}$ level Vulnerability Form (GNDT, 1993) and calculation of the Vulnerability Index, $I_{v}$. 
Since the empirical methods are conceived for a comparative purpose, it is important to set a survey procedure which ensures objectivity, in order to perform reliable comparisons among different structures: the procedure explained above tries to give all the instruments for this kind of activity.

\subsection{Results of the vulnerability survey campaign}

Considering the information collected during the surveys, it is possible to get an overview of the seismic vulnerability of the sample; the proposed results are related only to the masonry structures (118 S.U.).

Figure 1 shows the distribution of the period of construction of the masonry structures: most of the volume has been realized before 1950. In the second part of the last century, the construction using reinforced concrete started to become more common, reducing the realization of masonry structures.

Figure 2 instead shows the results obtained by the application of the Vulnerability Index Method for all the 118 S.U.: it is possible to observe a Gaussian distribution of the Indexes, with average value around $50 \%$. The values of $I_{v}$ mainly belong to the

Period of construction - ma sonry structures

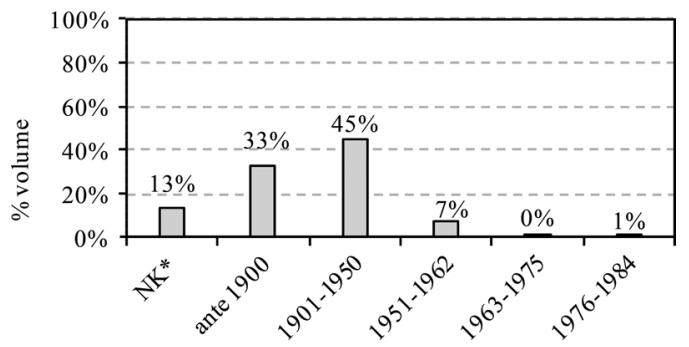

Figure 1. Distribution of the period of construction for the masonry structures. ${ }^{*} \mathrm{NK}=$ not known.

Distribution $I_{v}$-ma sonry structures

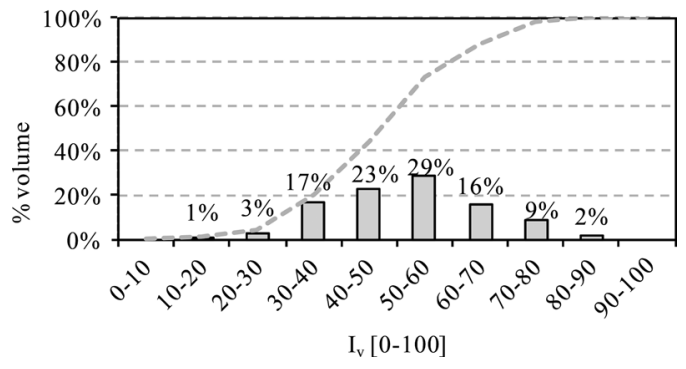

Figure 2. Distribution of $I_{v}$ for masonry structures.
[30\%;70\%] range (almost $85 \%$ of the structures), with maximum and minimum values respectively equal to $\mathrm{I}_{\mathrm{v} \text { max }}=81 \%$ and $\mathrm{I}_{\mathrm{v} \text { min }}=14 \%$.

Crossing the information about the historical period of construction and the $I_{v}$, it is possible to observe, in Figure 3, that the buildings realized before 1900show the highest quantity of volume in the vulnerability range $[50 \% ; 70 \%]$, while the more recent structures mainly belong to the vulnerability range $[40 \% ; 60 \%]$. Looking to the cumulative curves, the more recent structures appear on average less vulnerable, even if there are high vulnerable cases which invert the trend in the $[60 \% ; 90 \%]$ range.

\section{DETAILED ANALYSES}

\subsection{Introduction}

The Vulnerability Index Method is a popular method in Italy for the expeditious vulnerability assessment of wide samples of buildings: since the economical resources of each Administration are limited, in the aim of the seismic risk reduction, it is necessary to obtain a first general overview of the vulnerability for the considered sample, highlighting the most critical cases.

The method is used to get a classification of vulnerability of the analyzed structures: this ranking is a useful instrument for the Administrations, in order to decide which structures should be better analyzed at first by means of detailed analyses. On the other hand, this method cannot give results in terms of absolute values of the index of risk, since detailed analyses are required.

The idea of this work is to investigate the features of the Vulnerability Index Method and their relation with detailed analyses, in order to obtain more information about the seismic behaviour of the structures simply using an expeditious method of vulnerability assessment. For this purpose, starting from the entire sample of masonry structures,

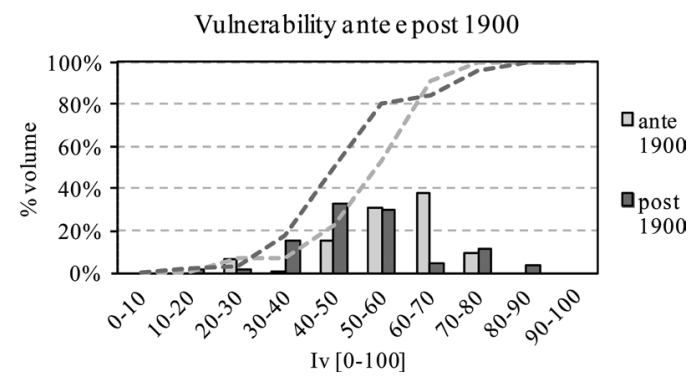

Figure 3. Distribution of $I_{v}$ considering the age of realization. 
composed of 118 S.U., it has been decided to investigate a subset composed of 20 S.U., which represents $17 \%$ of the entire masonry buildings sample in terms of number of S.U. and $42 \%$ of it in terms of volume.

The buildings have been chosen considering different construction technologies and different periods of realization, in order to take into account the widest range of structural configurations.

The chosen subset of S.U. (20 S.U.) covers a considerable part of the $I_{v}$ range of the entire masonry structures sample (118 S.U.), as shown in Figure 4, even if the extreme cases have not been considered as case studies. In particular, the entire sample of S.U. has values of $I_{v}$ in the range $[14 \%-81 \%]$, while the subset considers the range $[35 \%-71 \%]$.

In Figure 4, the S.U. are ordered following the relative ranking of vulnerability of the subset, starting from the most vulnerable unit (position 1) to the least vulnerable (position 20).

\subsection{Methodology of analysis}

The idea of the work is to study the relation among empirical and detailed analyses on masonry structures: in particular, it has been decided to focus on the global behaviour of the structures, assuming that each wall can react in its plane against the seismic action, due to the presence of a box behaviour ensured by effective connections among floors and walls. This assumption has been made considering the structural features of the analyzed buildings, which are often characterized by the presence of r.c. beams on the edges of the floors; the local analysis will be considered in an empirical way, in order to evaluate the reliability of the obtained results.

Before starting the creation of the numerical models, an additional survey on each of the 20 S.U. has been performed, in order to deepen the level of knowledge of the structural aspects: in particular, the typologies of masonries, floors and roofs have been better investigated, as well as the directions of the structural elements of each floor. Some infor-

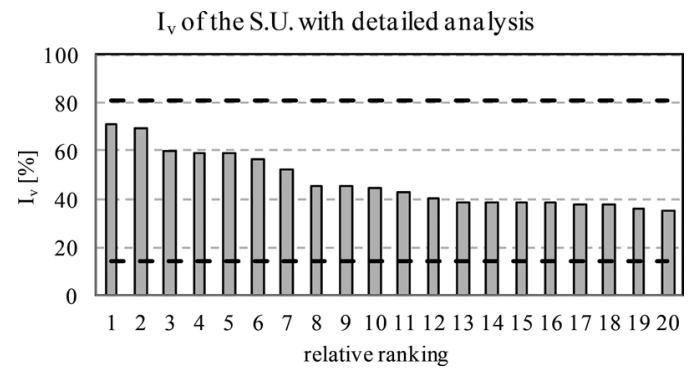

Figure 4. $I_{v}$ of the subset of masonry S.U.. The dashed lines represent the boundaries of the entire sample. mation has been obtained even through the use of a thermal image camera, allowing the identification of the typologies of masonry (when perfectly covered by plaster), typologies and directions of the structural elements of the floors, presence of openings filled with masonry etc...

In-situ tests have been not performed for the estimation of the mechanical properties of the materials: the numerical models have been realized using the masonry categories of the Italian Code (D.M. 2008 and C.M. 617/2009).

From the geotechnical point of view, no information about the ground conditions were available; it has been decided to consider a common reference soil, in order to avoid the introduction of another variable, focusing only on the structural vulnerability. In particular, it has been chosen to assume that all the buildings are in the best geotechnical category of soil ("A" type for D.M. 2008).

Three dimensional models have been realized to perform static non linear analyses: the F.M.E. (Frame by Macro Element) approach has been adopted, in which the structure is modelled as an equivalent frame structure, with non-linear behaviour elements; in particular, beams and columns which respectively represent the spandrels and the piers of the building.

The software 3MURI (Galasco et al, 2002), developed by STA.DATA, has been used to perform the pushover analyses.

For each S.U., several analyses have been realized, considering the two principal horizontal directions in both load application ways $(+\mathrm{X},-\mathrm{X},+\mathrm{Y}$, $-\mathrm{Y}$ ), two different types of pushing profile (proportional to the masses or to the $1^{\circ}$ modal shape) and the presence or absence of eccentricity of the pushing profile from the barycenter of the masses (5\% of the maximum dimension of the building, as requested by the Italian Code, considered on both sides from the barycenter of the masses).

The combination of the variables mentioned above creates 24 different analyses, which have been performed for all the 20 S.U..

Results are plotted for the worst 8 analyses, considering direction, pushing profile and presence or absence of eccentricity (see Table 2 for their definition).

\subsection{Main results}

Considering as example the S.U. shown in Figure 5, the results of the pushover analyses are described.

In Figure 6, the pushover curves obtained for the S.U. shown in Figure 5 are plotted: it is possible to observe that the $\mathrm{Y}$ direction is the weakest, since the maximum shear strength $F_{b}$, normalized to the weight of the structure $W_{t o t}$, is lower than the cases of the $\mathrm{X}$ direction. 
Table 2. Results of the example of Figure 5 in terms of structural capacity.

\begin{tabular}{lllll}
\hline N. & Direction & Profile & Eccentricity & PGA $_{\mathrm{c}}[\mathrm{g}]$ \\
\hline 1 & $\mathrm{X}$ & $1^{\circ}$ modal shape & $0 \%$ & 0.32 \\
2 & $\mathrm{X}$ & masses & $0 \%$ & 0.43 \\
3 & $\mathrm{X}$ & $1^{\circ}$ modal shape & $5 \%$ & 0.31 \\
4 & $\mathrm{X}$ & masses & $5 \%$ & 0.41 \\
5 & $\mathrm{Y}$ & $1^{\circ}$ modal shape & $0 \%$ & 0.12 \\
6 & $\mathrm{Y}$ & masses & $0 \%$ & 0.16 \\
7 & $\mathrm{Y}$ & $1^{\circ}$ modal shape & $5 \%$ & 0.12 \\
8 & $\mathrm{Y}$ & masses & $5 \%$ & 0.14 \\
\hline
\end{tabular}

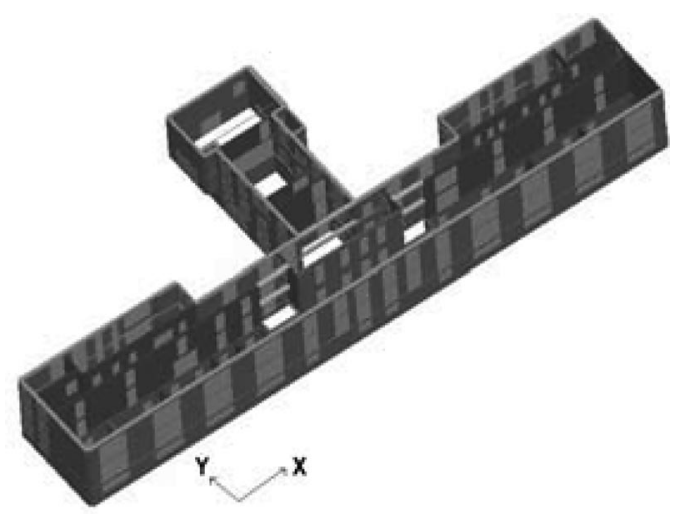

Figure 5. Example of the $3 \mathrm{~d}$ model of a S.U. of the subset.

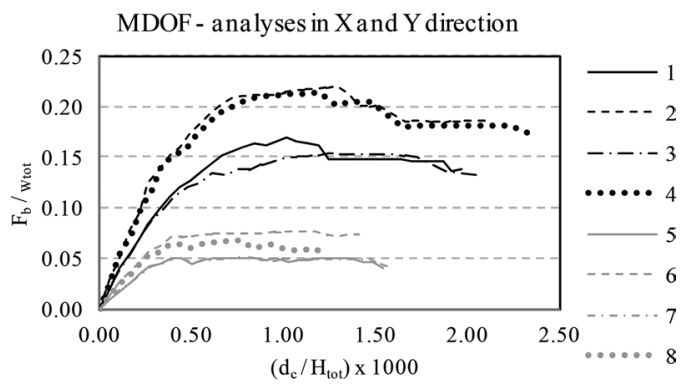

Figure 6. Pushover curves of the S.U. shown in Fig. 5.

Even the maximum displacement of the control point $d_{c}$ (usually chosen on the roof, close to the barycenter of the plan), normalized to the maximum height of the structure $H_{t o t}$, is smaller for the $\mathrm{Y}$ direction than the $\mathrm{X}$ one. This behaviour is due to the absence of continuous transversal internal walls.

The procedure of normalization is required in order to compare the graphs of different buildings.
The PGA of capacity has been evaluated for each curve, starting from the last displacement $\left(d_{u}\right)$ offered by the structure in the capacity curve and scaling the reference demand spectrum. Results are shown in Table 2.

As shown in Table 2, the lowest value of the PGA is provided by the analyses in the $\mathrm{Y}$ direction.

For all the $20 \mathrm{~S} . \mathrm{U}$. of the subset, the minimum value of the $\mathrm{PGA}_{c}$ has been evaluated, in order to compare it with the relative $I_{v}$.

Figure 7 shows the minimum $\mathrm{PGA}_{\mathrm{c}}$ for all the 20 S.U. analyzed in detail by means of pushover analyses. As seen in figure 4, the S.U. are ordered following the relative ranking of vulnerability of the subset, starting from the most vulnerable unit (position 1) to the least vulnerable (position 20).

It is important to highlight that the rankings of the two methods do not coincide completely: this aspect is related to the differences among the two procedures, since the detailed analysis concerns only structural aspects while the empirical one includes also non structural features; the different levels of detail of the methods influences the results as well.

\section{COMPARISON AMONG EXPEDITIOUS AND DETAILED METHOD}

\subsection{Comparison among the methods}

For each of the 20 analyzed S.U., the couples $\left(I_{v}, \mathrm{PGA}_{c}\right)$ have been plotted as shown in Figure 8, in order to study the relation among the two quantities. It has been observed that an exponential trend fits the cloud of point.

The curve gives qualitative correct information: vulnerable structures (high values of $I_{v}$ ) are associated to low $\mathrm{PGA}_{\mathrm{c}}$ values and, on the other side, not vulnerable structures can reach high $\mathrm{PGA}_{\mathrm{c}}$ values. Starting from the $I_{v}$, the application of the equation for the estimation of the $\mathrm{PGA}_{\mathrm{c}}$ leads to considerable errors, up to $+/-28 \%$.

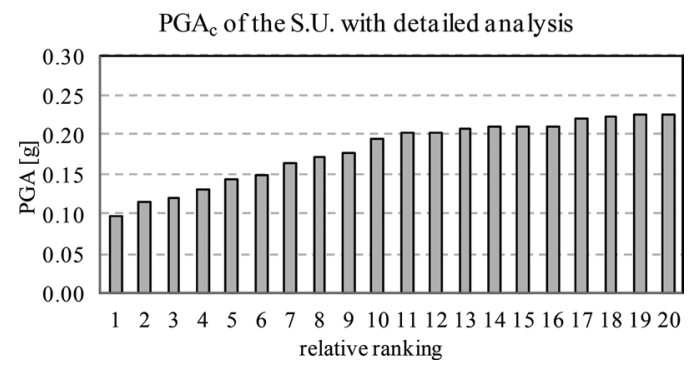

Figure 7. PGA $_{\mathrm{c}}$ of the subset of masonry S.U. 


\subsection{Re-calculation of the Index of Vulnerability}

The equation shown in Figure 8 appears not reliable for a first estimation of the capacity using as input the $I_{v}$, due to the considerable level of error.

The two methods have been better compared, in order to highlight the differences; in particular, referring to the parameters of the Vulnerability Index Method, it has been observed that some of them, for their definition, are implicitly assumed as in the best condition in the detailed approach:

- parameter 1 , which considers the presence and quality of the connections among walls, or, in other words, the possibility of a global behaviour of the structure, can be considered always as in the best condition in the detailed models, since three dimensional models are realized without taking into account the activation of local out of plane mechanisms;

- parameter 4, related to the geotechnical condition, can be considered in the best condition too, since the numerical models are realized with fixed restraints to the ground level, on a common soil with high mechanical characteristics ("A" category-D.M. 2008);

- parameter 8, related to the possibility of activation of local out of plane mechanisms, is not considered in the $3 \mathrm{~d}$ models;

- parameters 10 and 11 , related to non structural elements and state of conservation (plaster condition, humidity problems etc...) are not considered in the numerical models.

Considering the aspects described above, it has been decided to calculate a new vulnerability index, in order to perform a more reliable comparison among the methods: the new vulnerability index is based on the original judgments for the parameters included in the detailed approach, while for the other ones (listed above) the best judgment has been assigned.

New values of $I_{v}$ have been obtained and a new comparison is proposed in Figure 9.

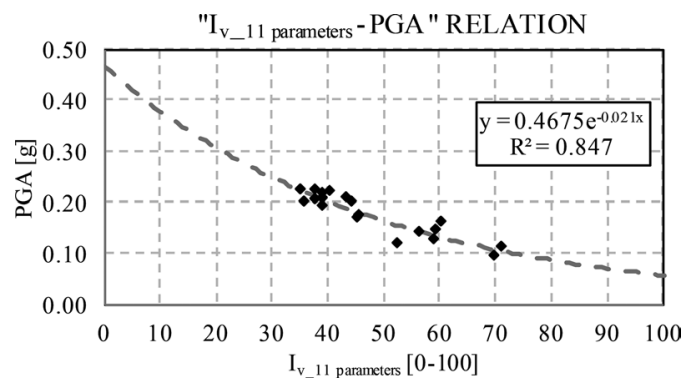

Figure 8. Relation among detailed and empirical method.
Another exponential trend line has been obtained, which better fits the cloud of points: the application of the new equation for the estimation of the $\mathrm{PGA}_{c}$, starting from the new $I_{v}$ (6 parameters) leads to errors up to $+/-21 \%$. The approximation is more reliable since the same variables are considered.

\subsection{Conclusion on the performed comparison}

The results have highlighted that there is a relation among the Vulnerability Index Method and the detailed approach (static non-linear analyses); the relation is stronger if only the parameters of the expeditious method concerning the global behaviour of a structure are considered, since this assumption allows a more direct comparison among the methods.

A part of the difference among the methods' results may be attributed to the values of the weights (Table 1).

\section{DEVELOPMENT OF A NEW EXPEDITIOUS VULNERABILITY ASSESSMENT METHOD}

\subsection{Critical analysis of the original method}

Before developing a new method, the relations among the parameters and their influence in a detailed analysis have been studied.

Considering the original method's weights and supposing that a building is characterized by the worst conditions for each parameter $\left(I_{v}=100 \%\right)$, it has been observed that:

- parameter 2 has a maximum influence of almost $3 \%$ in the vulnerability evaluation, even if, in a structural analysis, it plays a key role;

- parameter 3 is the most influent parameter, since it considers the quantity of resistant systems;

- parameters 5 and 9 have the same influence, without considering the number of floors.

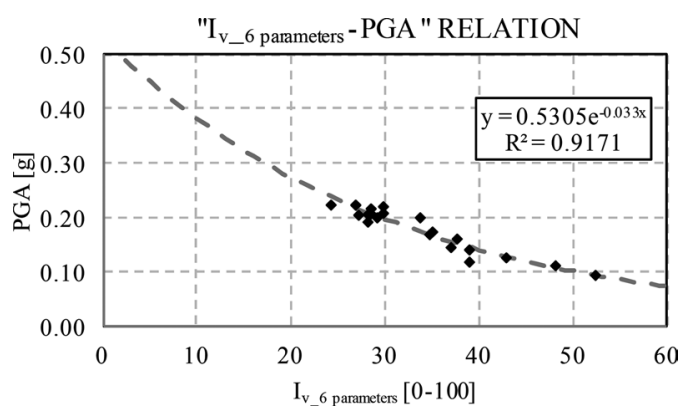

Figure 9. Relation among detailed and modified empirical method. 
Analogous considerations are valid taking into account only the six parameters related to the global analysis. The following analyses concern the six parameters which have been used before in the correlation analysis: parameters $2,3,5,6,7,9$.

\subsection{Definition of the new parameters}

In order to calibrate the new weights for the expeditious method, it has been decided to evaluate the relation among the results of the detailed analysis and the values of the "lateral resistance indicator", defined in this work as the product among the shear strength $t_{k}$ of the type of masonry (referring to the values proposed in the Italian Code) and the ratio $a_{0}=A / A_{t}$, with $A=$ minimum cross section area of the resistant systems of the S.U., considering the two main directions and each level of the structure separately, and $A_{t}=$ global area of the considered level.

The relation among the two variables is high (Figure 10): this new variable (lateral resistance indicator), called $x_{1}$, will be used in the new proposal, substituting the parameters 2 and 3 .

Another aspect that has been modified is the relation among the parameters 6 and 9: floors and roofs. In the original method, they have the same influence but, considering as example a two and a five storey buildings, the roof cannot play the same role in the two cases, in particular for structures which are characterized by rigid floors and roofs (as the most of the buildings of the considered sample). For this reason, a linear combination of the two parameters is adopted, creating the new variable $x_{2}$, in order to take into account the relative importance of the roof and floors (Equation 1):

$$
(P 5+P 9)=\frac{P 5 \cdot\left(n \cdot^{\circ} \text { floors }-1\right)+P 9 \cdot(1)}{n .^{\circ} \text { floors }}
$$

Parameters 6 and 7, concerning the regularity in plan and height of the structure, are used as in the original method, defining the variables $x_{3}$ and $x_{4}$.

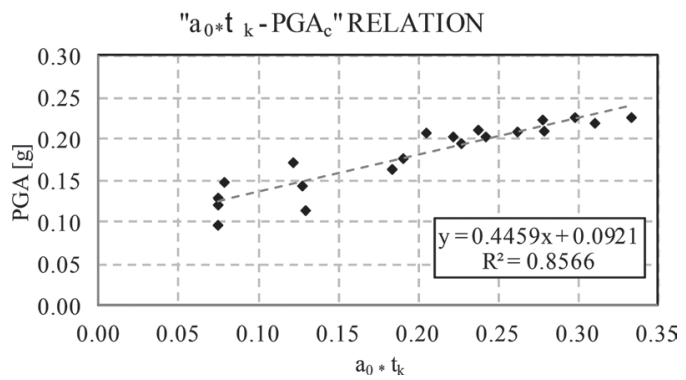

Figure 10. Relation among the lateral resistance indicator and the $\mathrm{PGA}_{\mathrm{c}}$ obtained by the detailed analyses.
Resuming, four parameters are considered in a qualitative way, as in the original expeditious method (parameters 5, 6, 7 and 9), while other two (parameters 2 and 3 ) are included in a continuous variable, the lateral resistance indicator. In conclusions, four new variables $x_{i}$ have been individuated.

\subsection{Development of the new expeditious vulnerability assessment method}

Since the new weights of each parameter must be calculated with an optimization of the available data, the scores of the qualitative parameters have been defined in an arbitrary way, without using the ones proposed by the original method. The relative importance among the parameters has been evaluated, calculating the weights which better optimize the correlation among empirical and detailed data. A multi-linear regression has been used (Equation 2):

$$
y=\sum_{i} m_{i} \cdot x_{i}+b
$$

where $m_{i}$ represent the weights of each independent variable $x_{i}$ and $b$ is a constant value; $y$ repre-

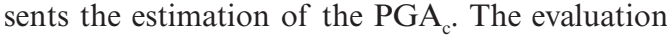
of the $m_{i}$ and $b$ is performed with the least squares technique.

The results have given the values (Equation 3):

$$
\begin{aligned}
y=\sum_{i} m_{i} \cdot x_{i}+b= & 0.3364 x_{1}+0.0168 x_{2}+0.0041 x_{3} \\
& +0.0053 x_{4}+0.0524
\end{aligned}
$$

The maximum error, registered on the analyzed S.U., is lower than $+/-15 \%$ (Figure 11). Tests have been performed on several case studies, which have confirmed maximum errors up to $+/-15 \%$.

Since local out of plane mechanisms can represent the minimum capacity for masonry structures

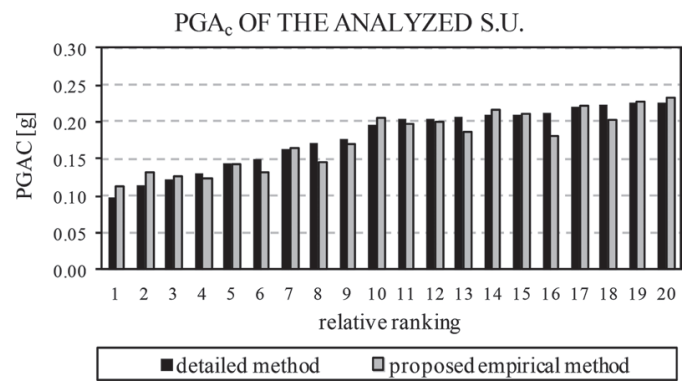

Figure 11. Comparison among the results of the detailed method and the proposed empirical method. 
Table 3. Maximum percentage of influence of each parameter.

\begin{tabular}{lll}
\hline N. & Parameter & $\%$ \\
\hline 1 & $\begin{array}{c}\text { Type and organization of the resistant } \\
\text { system }\end{array}$ & 11.8 \\
2 & Quality of the resistant system & 2.9 \\
3 & Conventional resistance & 17.6 \\
4 & Position of the building and foundation & 8.8 \\
5 & Typology of floors & 11.8 \\
6 & Planimetric configuration & 5.9 \\
7 & Elevation configuration & 11.8 \\
8 & Maximum distance among the walls & 2.9 \\
9 & Roof & 11.8 \\
10 & Non structural elements & 2.9 \\
11 & State of conservation & 11.8 \\
\hline & & $100 \%$
\end{tabular}

which cannot show a box-behaviour, a reliability index of the estimation provided by the new proposal has been conceived, using the judgments of parameters 1,5 and 8 of the original Vulnerability Index Method (parameters directly related to the possibility of activation of local out of plane collapses):

$$
R_{I}=1-\frac{\sum_{1,5,8} V_{i} \cdot P_{i}}{101.25}
$$

Four ranges for $\mathrm{R}_{\mathrm{I}}$ have been identified: lower than $25 \%, 25 \%-50 \%, 50 \%-75 \%$ and higher than $75 \%$. In the first two ranges, $\mathrm{R}_{\mathrm{I}}$ highlights a low reliability of the global capacity estimation, since local problems may rule the behaviour of the considered structure; the $3 \mathrm{rd}$ range $(50 \%-75 \%)$ belongs to structure for which the global approach starts to be reliable, while the 4 th range $(75 \%-100 \%)$ mainly refers to structures realized with technological features able to exclude local mechanisms' problems.

Most of the analyzed structures of the sample are characterized by $R_{I}$ belonging to the $3 \mathrm{rd}$ and 4th ranges, due to their structural organizations, which are often characterized by the presence of rigid and well connected floors at each level. For the buildings with $\mathrm{R}_{\mathrm{I}}$ belonging to the 1 st and 2 nd range (historical buildings, realized with disorganized stone masonry and deformable floors), the estimation of the $\mathrm{PGA}_{\mathrm{c}}$ is not representative of the structural capacity, since local mechanisms represent the main problem, but it gives an indication about the global performance that the structure would have after the necessary interventions against out of plane mechanisms.

\section{CONCLUSIONS}

Considering the results of the empirical method of the Vulnerability Index (GNDT, 1993) applied on a wide sample of masonry hospital structures, a subset of structures have been chosen in order to perform detailed analyses for the vulnerability estimation; comparisons among the two methods have been performed and, through a critical analysis of the Vulnerability Index Method, a new proposal has been developed, using the same information required by the original empirical method. An estimation of the $\mathrm{PGA}_{\mathrm{c}}$ for the global behaviour (with the related reliability index) can be obtained, allowing the calculation of an absolute index of risk as the ratio among capacity and demand accelerations.

The method is useful for territorial approaches in case of masonry structures' samples mainly characterized by global behaviour. Classifications of vulnerability and risk can be obtained: these rankings are useful instruments in order to decide which structures analyze at first with a detailed approach.

\section{REFERENCES}

Benedetti D., Petrini V. (1984). Sulla vulnerabilità di edifici in muratura: proposta di un metodo di valutazione. L'industria delle Costruzioni, Vol. 149, No. 1, pp. 66-74.

Chinni C., Mazzotti C., Savoia M., Perri G. (2013). RE.SIS.TO®: una metodologia speditiva per la valutazione di vulnerabilità sismica di edifici in muratura e calcestruzzo armato. Atti del XV Convegno ANIDIS. Padova 2013.

D.M. 2008. Decreto Ministeriale Infrastrutture del 14/01/2008.

Formisano A., Mazzolani F.M. (2009). Vulnerabilità sismica di un aggregato in muratura in Sessa Aurunca. Atti del XIII Convegno ANIDIS. Bologna 2009.

GNDT (1993). Rischio sismico di edifici pubblici, Parte I: aspetti metodologici. Proceedings of CNR - Gruppo Nazionale per la Difesa dai Terremoti, Roma, Italia.

Galasco A., Lagomarsino S., Penna A. (2002). TREMURI Program: Seismic Analyser of 3D Masonry Buildings. University of Genoa.

Grünthal, G. (1998). EMS 1998. Cahiers du Centre Européen de Géodynamique et de Séismologie, Luxembourg.

Vicente R., Parodi S., Lagomarsino S., Varum H., Mendes J.A. (2011). Seismic vulnerability and risk assessment: case study of the historic city centre of Coimbra, Portugal. Bullettin of Earthquake Engineering (2011) 9:1067-1096.

Whitman R.V., Reed J.W., Hong S.T. (1973). Earthquake Damage Probability Matrices. Proceedings of the 5th WCEE, Rome, Italy, Vol. 2, pp. 2531-2540. 